Relmecs, junio 2017, vol. 7, no. 1, e021, ISSN 1853-7863

Universidad Nacional de La Plata. Facultad de Humanidades y Ciencias de la Educación. Centro Interdisciplinario de Metodología de las Ciencias Sociales.

Red Latinoamericana de Metodología de las Ciencias Sociales

\title{
El pensamiento complejo y transdisciplinario como marcos de investigación científica
}

\author{
The complex and transdisciplinarity thought as frames of scientific \\ research
}

\author{
Elvio Galati (*) \\ * Centro de Altos Estudios en Ciencias Sociales, Universidad Abierta Interamericana (UAI), Argentina | \\ elviogalati@gmail.com
}

\section{PALABRAS CLAVE}

Metodología

Pensamiento Complejo

Transdisciplinariedad

Investigación Científica

Multimétodos

Ciencias Sociales

\section{KEYWORDS}

Methodology

Complex thought

Transdisciplinarity

Scientific research

Multi-methods

Social sciences

\section{RESUMEN}

El trabajo pretende describir, fundamentando, desde el punto de vista metodológico, el pensamiento complejo de Edgar Morin y la transdisciplinariedad de Basarab Nicolescu. Se estructura planteando los contextos filosófico y lógico del multimétodos; y luego desarrollando ideas metodológicas a partir de la transdisciplinariedad y la complejidad. La metodología empleada es la documentación, teniendo en cuenta artículos de doctrina y la experiencia docente. Hay análisis del discurso, clasificación e interpretación, creándose también categorías. Se ven las implicancias de la filosofía integradora, compleja y transdisciplinaria, en un diseño de investigación para Ciencias Sociales. Se aporta la categoría transdisciplinar de la propiedad, sumándola a la de producción. Desarrollando la complejidad y la transdisciplinariedad como metodología, se plantean "consignas transdisciplinares" aplicadas a la investigación aunque pensadas originariamente para la enseñanza. A partir de la estructura del diseño de investigación, se señalan estrategias metodológicas transdisciplinares asistemáticas, y sistemáticas, elemento por elemento del proyecto de investigación. Como otro de los resultados se agrega la creación de la categoría de Teoría General/Provisoria de la Ciencia, encarada desde la transdisciplinariedad.

\section{ABSTRACT}

The work aims to describe and support, from the methodological point of view, Edgar Morin's complex thought and Basarab Nicolescu's transdisciplinarity. It is structured based on the philosophical and logical contexts of multi-method; and then developing methodological ideas from transdisciplinarity and complexity. The methodology used is the documentation, taking into account articles on doctrine and teaching experience. There is discourse analysis, classification and interpretation, also creating categories. The implications of integrative, complex and transdisciplinary philosophy are seen, in a research design for Social Sciences. Transdisciplinary category of "property" is provided, adding it to the "production" category. Developing the complexity and transdisciplinarity as a methodology, "transdisciplinary instructions" arise, which are applied to research although they were originally thought for teaching. From the structure of the research design, unsystematic transdisciplinary methodological strategies and systematic strategies element by element of the research project are identified. As another result, the creation of the category of "General Theory / Interim Science" is added, approached from transdisciplinarity. 


\section{Introducción}

La idea de este trabajo es fundamentar, encuadrar y precisar a las llamadas inter o transdisciplinariedad como herramientas metodológicas para aplicar a una investigación concreta. En una época de explosión disciplinaria ${ }^{1}$, que es simultánea a la explosión metodológica, es necesario encontrar medidas de salvaguarda para la búsqueda de conocimientos coherentes a la necesidad de la integración.

El contexto teórico del proyecto de investigación se valdrá del pensamiento complejo en tanto es difícil asociar la integración metodológica con la simplicidad, en donde las disciplinas están separadas, celosas de sus territorios conquistados, estableciendo aduanas y derechos de exportación e importación académicos. Es mi intención fundamentar y encuadrar, desde el punto de vista metodológico, a la complejidad de Edgar Morin y a la transdisciplinariedad de Basarab Nicolescu, ya que estas teorías tienen pautas, criterios o pistas metodológicas. El científico integra si constantemente busca ayudas de sus vecinos académicos. La metodología tendrá en cuenta la documentación, y el análisis del discurso y la hermenéutica. En una etapa posterior, las unidades de análisis serán casos testigos significativos que demuestren articulación disciplinaria, utilizando metodologías y aplicaciones de la complejidad y la transdisciplinariedad en las áreas de estudio sociales.

\section{Contexto filosófico del multimétodos. Complejidad y simplicidad en Metodología}

Así como la medicalización de la vida significa que la Medicina absorba las relaciones humanas, medicando lo que no hay que medicar, y la juridización del Derecho hace lo propio pero desde el ámbito jurídico², la cientifización no debe traducirse en metodologización, es decir, querer encerrar la investigación en reglas metodológicas, previendo, planificando todos los pasos en la investigación. El método es para la investigación, pero no la investigación para el método. Sobre todo frente a avances racionalistas, metodologicistas, que pretenden incluso hasta incluir y avanzar resultados en proyectos de investigación.

Cabe preguntarse si hay que investigar por disciplinas o integrando. Max Weber es un ejemplo de cómo es posible articular la práctica religiosa con la actividad económica, lo que expuso en "La ética protestante y el espíritu del capitalismo”. Follari defiende la disciplinarización confrontándola con la interdisciplinariedad, en tanto el autor plantea que los lenguajes de las ciencias son mutuamente intraducibles en el sentido kuhniano (2001, p. 42). Hay que sumar aquí la opinión de Hans Kelsen, que pensaba que el Derecho estaba compuesto únicamente por normas. A su vez, criticaba que “(...) su prestigio científico [del jurista] se jerarquiza al tomar en préstamo conocimientos de otras disciplinas” (Kelsen, 1992, p. 16). El jurista de Viena nos dice que “(...) la sociedad es una realidad totalmente distinta de la naturaleza” (Kelsen, 1992, p. 16) y por ende “(...) opone las ciencias sociales a las ciencias de la naturaleza y ve (...) en la sociedad un orden o un sistema diferente de la naturaleza” (Kelsen, 1992, p. 17).

Cuando Juan Arana se pregunta si es posible la interdisciplinariedad, señala distintos obstáculos a superar: el entendimiento a través de expresiones y lenguajes para quienes no pertenecen a la disciplina, siendo que a veces es difícil el entendimiento entre los que sí pertenecen; el trabajo en equipo y la división racional del trabajo; la especialización y sus ventajas, como el dominio (poder) del tema y el lucro (Arana, 2001). Para ello, una estrategia puede ser la discusión en el plano ontológico, y no en el terminológico $\underline{3}$ (Arana, 2001), en tanto las discusiones en éste último suelen ser interminables, mientras que el tratamiento del ser de los problemas ayuda a la iluminación de la temática con sus necesidades.

También se habla de hacer justicia a la diferencia, en tanto se fundiría la especificidad disciplinar en una mezcla donde desaparecería toda peculiaridad 4 (Follari, 2001, p. 44). Recuérdese que “(...) la interdisciplinariedad tropieza con los intereses gremiales de los especialistas, las ambiciones territoriales de los académicos y el desinterés para todo lo que no sea el corto plazo de los administradores públicos” 
(Arana, 2001). El lema que comenzó Descartes y que siguieron Voltaire, Diderot y Montesquieu fue no confundir los objetos de conocimiento, los que debían percibirse en su diferencia (Buguet, 2003, p. 134). “Nous sommes dans le registre de l'analytique où la décomposition est de rigueur프" (Buguet, 2003, p. 135). Reducir el todo a una parte no lleva más que a ocultar (Buguet, 2003, p. 135) aquello que queda mutilado. A propósito de esta idea, un metodólogo señala concordantemente que el saber está bordeado por el no-saber y que la interdisciplina se apoya en la diferencia, que ella misma contribuye a explicitar para formalizar una nueva episteme (Resweber, 1981, p. 123). ¿Se trata de un apoyo o de un feudo la disciplina? Parece que “(...) les disciplines ne sont pas seulement un moyen commode de diviser les connaissances en éléments, elles sont aussi la base sur laquelle l'université s'organise en fiefs autonomes qui définissent les différentes spécialités de l'enseignement et de la recherche ${ }^{6}$ "' (Gass, 1972, p. 7). He aquí una desventaja particular que se integra, para perfeccionar el conocimiento. También se muestra como crítica a la interdisciplina que la síntesis operada estaría sesgada por la mente del que la realiza, funcional a su propia formación (Follari, 2001, p. 44). De ahí que la transdisciplinariedad, en tanto tiene como etapa previa a la interdisciplinariedad, sugiere el trabajo en equipo, a la manera de un grupo de formación o de una red, en donde el aporte de cada uno es necesario para la producción común, a la espera de satisfacer las expectativas recíprocas (Demol, 2003, p. 42). "La transdisciplinarité appliquée devient difficilement concevable sans investissement personnel (discipline interne) et sans solidarité (interaction) ${ }^{\underline{7}}$ ”, (Demol, 2003, p. 42). Algunos sostienen, y es para pensar, que una misma persona, que enseña varias disciplinas, y que las combina en función de las necesidades, no es un signo de interdisciplinariedad (Berger, 1972, p. 37), y por ende de transdisciplinariedad.

En tren conciliador se señala que no se trata de destruir la enseñanza organizada en disciplinas, sino de enseñarlas en función de su relación dinámica con las otras disciplinas y con los problemas de la sociedad. Los costos sociales crecientes de la extrema especialización justifican esta concepción (Gass, 1972, p. 8). "Se trata (...) a partir de un principio de complejidad, de unir lo que estaba disjunto” (Morin, 1993, p. 37). En el caso de Weber y el espíritu del capitalismo, por ejemplo, esto se ve en relación que el filósofo estableció entre aspectos de la economía y aspectos de la religión. Más allá del acierto o no de la idea, importa la conexión y cómo a su vez se da la polémica con Marx, que piensa a la economía como un condicionante muy influyente del resto de las áreas de la vida.

Hay que tener en cuenta cómo Max Weber, en Economía y Sociedad, asocia la disciplina a la dominación y cómo la indisciplina es la base de la complejidad, en tanto la actitud transdisciplinaria es la que no respeta, pero reconoce, las fronteras. También se expresa que las fronteras que establecen las disciplinas no se corresponden con demarcaciones que existen en la realidad misma, ya que son resultado de las convenciones de los investigadores.

Se habla también de la "división social del conocimiento", que proviene de la división social del trabajo (Comesaña, 2001, pp. 68-69). No parece irrazonable lo que señala Juan Manuel Comesaña en cuanto a que la complejidad sería propia de una época que ahora no existe, el Renacimiento, debido a la atomización progresiva de los campos del conocimiento, lo que incrementaría las apelaciones a la autoridad que sí son falaces (Comesaña, 2001, p. 69). Hay que tener en cuenta que ver a la ciencia como lo que solo existe o lo que es posible, reduciría mucho su ámbito, algo que no ocurrió, por ejemplo, frente a quienes se plantean utopías e incluso tratan de realizarlas, como Martin Luther King, los jóvenes estudiantes y obreros del Mayo Francés $\underline{\underline{8}}$, los jóvenes argentinos de la Reforma Universitaria de 1918, etc. Es posible hablar científicamente de los valores o utopías.

Sumando críticas a la labor interdisciplinaria, se expresa que, o es efectuada por una sola persona que debe adquirir conocimientos que no tenía antes, lo que exige mucho tiempo y no es rentable, o es confiada a un 
grupo en donde los miembros tendrán necesidad de un largo tiempo de aculturación interno antes de poder comenzar a trabajar en equipo (Apostel, 1972, p. 173). En primer lugar, el trabajo en equipo se plantea antes de la interdisciplina, y es de por sí una metodología. En cuanto al trabajo en soledad, se tendrá que prever cómo se planifican tantas cosas a la hora de encarar una investigación. Y se alega que por la novedad metódica que implica dicho trabajo no es posible fundar las previsiones sobre trabajos anteriores (Apostel, 1972, pp. 173-174), lo que aumenta la novedad del aporte al conocimiento y consiguiente avance de la ciencia.

Cabe preguntarse también si la interdisciplina implica un trabajo en equipo de los profesionales pertenecientes a distintas disciplinas, ya que nadie es personalmente interdisciplinar. De lo contrario, se darían larvadas hegemonías disciplinares (Follari, 2001, p. 44). Un ejemplo de trabajo que daría lugar a la articulación disciplinar es un comité de bioética hospitalario, en donde en muchas ocasiones hay una hegemonía de trabajo titularizada en el saber médico ${ }^{\underline{9}}$. Algunos dan a la problemática como resuelta y obvia a su respuesta: “(...) un equipo interdisciplinario es un grupo” (Stolkiner, 1999). Por otro lado, han existido esfuerzos de naturaleza interdisciplinar de una sola persona, como el caso del jurista Werner Goldschmidt, tributario de ideas tridimensionalistas: “(...) une même personne peut s’adonner à plusieurs sciences $\underline{10}$," (Apostel, 1972, p. 154).

A grandes rasgos, la idea que abraza la combinación o la creación a partir de la integración es la de romper las barreras de protección que cada disciplina tiene con respecto a la otra (Resweber, 1981, p. 79), diferenciar y comparar los métodos y no estar obsesionados por los instrumentos de conocimiento clásicos (Resweber, 1981, p. 81). "Le spécialiste, quand à lui, s'accommode fort bien d'un tel discours qui le sécurise, le protège et derrière lequel il s’abrite ${ }^{11 \text { ” }}$ (Resweber, 1981 p. 135). En efecto, la investigación se hace por las interacciones múltiples de las fuentes de los saberes (Galvani, 2005, p. 37). En cuanto al método, “(...) no puede formarse más que durante la búsqueda (...)” (Morin, 1993, p. 36). De ahí que sin dejar de ser riguroso, hay que ser flexible a la hora de evaluar proyectos de investigación, dando primacía a la originalidad, en lugar del control burocrático. Morin habla en La vía... de la “desburocratización”; esta guarda relación con la desmetodologización y más ampliamente con la descientifización, es decir, con el límite a la obsesión y el lugar común de querer ver todo a través de la Epistemología. Así como en la Edad Media la humanidad estuvo absorbida por la santidad en el marco de la religión, con las nefastas consecuencias que ello trajo, habría que evitar la absorción por la verdad de los otros ámbitos de la vida. Peor aún, de la verdad como la ve la ciencia, mientras que la verdad es más que ciencia, de ahí la necesidad de la Gnoseología.

La integración tiene mucho que ver con la flexibilidad propia de la tradición cualitativa, en tanto el núcleo de toda investigación es su hipótesis, que en el caso del cualitativismo es lo que más cambios puede llegar a adoptar en el transcurso de la investigación. Pichon-Rivière, cuando analiza el proceso creador y los torbellinos que se generan a raíz de la creación, explica las idas y vueltas: "la obra (...) ha seguido un curso no rectilíneo, sino dialéctico. Se embarca en el tobogán de la espiral, creando, destruyendo el objeto estético para reconstruirlo en un nivel diferente y con técnicas diferentes” (Pichon-Rivière, 2005, p. 26).

Hoy en día, en tiempos "postmodernos", donde se critica la idea de "disciplina” nacida al calor de la Modernidad $\underline{12}$, es difícil concebir un conocimiento disciplinarmente aislado. "La significación del pensamiento postmoderno es el intento de explorar concepciones alternativas de conocimiento a las tradicionales (...)” (Mourad, 1997, p. 3). Además, pensadores como Michel Foucault han criticado lo relativo al poder que encierra la disciplina y su impronta normalizadora $\underline{13}$ (Mourad, 1997, p. 7). Más allá del hecho de que todo saber encierra poder, la idea sería complejizar y tratar de dialogizar los principios de unicidad, especialización e integración (Teves, 2009). 
La razón profunda que va en contra del multimétodos es la idea que sostiene la parcelización del conocimiento, es decir, el postulado según el cual se conoce mejor si se separa al "todo" en partes, que proviene de la filosofía de Descartes que sostiene el atomismo. Señalaba el pensador francés: “(...) dividir cada una de las dificultades a examinar en tantas partes como fuera posible y necesario para su mejor solución” (Descartes, 1993, p. 25). Cuando en realidad, las limitaciones de cada herramienta metodológica se solventan o compensan con las potencialidades de las otras $\underline{14}$ (Cea D’Ancona, 1999, p. 57).

No podemos descuidar el aporte contemporáneo de Edgar Morin a la complejidad, que precisamente trata de volver a unir aquel objeto despedazado por la ciencia moderna. Se separa el sujeto del objeto y en el objeto se da la separación de aspectos en donde uno de ellos funda la disciplina, mientras que las otras disciplinas no son otros objetos, sino aspectos que pueden ayudar a comprender al "objeto" en cuestión. Los objetos de estudio se construyen y ahora se los puede construir interdisciplinarmente. Si Goldschmidt pudo construir un fenómeno jurídico complejo con distintos aspectos: sociológico, normológico y dikelógico, lo propio se puede hacer en otros campos de estudio. Piénsese en la Epistemología, ampliada ahora a otros aspectos, distintos del lógico, que supo conformar el contexto de justificación, para incluir entonces el de descubrimiento y el de aplicación o valorativo. Si el objeto forma una totalidad organizada, sus elementos no son separables y estudiados aisladamente (García, 2006, p. 21). Cuando las asignaturas hablan de “integración curricular", habrá entonces que integrar al sujeto al estudio, y a los aspectos dejados de lado y que toman otras "disciplinas" que bien pueden llamarse otras "miradas”.

La perspectiva compleja también implica hablar de interrelaciones que son posibles si se ve a la metodología desde un punto de vista sistémico, en donde las partes forman un todo que hace posible relaciones que no son simples, lineales, unidireccionales, sino intercambios, préstamos, concurrencias, complementariedades. Así, veremos que una herramienta metodológica se da en distintos tipos de metodologías, que las variantes metodológicas se complementan y ayudan, que lo que se aplica en un elemento del diseño de investigación sirve también para otros elementos, que no hay un primer elemento y otro segundo, sino pasos que se pueden dar sucesiva o simultáneamente.

La interdisciplina también será la base que sustente la combinación metodológica que apoyo en el multimétodos. Así, “(...) una investigación interdisciplinaria supone la integración de estos diferentes enfoques (...)” (García, 2006, p. 33). En otras palabras, "estas interacciones entre la totalidad y las partes no pueden ser analizadas fraccionando el sistema en un conjunto de áreas parciales que correspondan al dominio disciplinario de cada uno de los elementos” (García, 2006, p. 88). Así como un árbol interesa a la reforestación, la carpintería, la pintura, la poesía, la química, todas las perspectivas ayudan, pero en ninguna de ellas puede cerrarse la comprensión de lo que el árbol es (Galvani, 2005, p. 17). De ser así se privilegiaría la división en las disciplinas, con riesgo de no estudiar aspectos importantes de ciertos fenómenos, en lugar de "delimitar” el objeto en función de las necesidades de los conocimientos que tengamos. Así, “[(...) definimos primero el objeto de estudio y luego nos planteamos la manera de estudiarlo” (García, 2006, p. 88). De ahí que sea perjudicial, en tanto prejuicioso, ubicar un tema de investigación en una disciplina. Morin (2011) ha puesto en práctica dicha idea cuando se plantea las "vías para la reforma de la humanidad", mencionando distintas problemáticas, no asociadas a disciplinas: la cuestión democrática, la demografía, los pueblos indígenas (sic), la ecología, el agua, la economía, desigualdades y pobreza, desburocratización, justicia y represión, salud, ciudad y hábitat, agricultura y mundo rural, alimentación, consumo, trabajo, la familia, la condición femenina, la adolescencia, la vejez y la muerte. Hay que organizar los programas alrededor de problemas-eje (Galvani, 2005, p. 23), porque las disciplinas se han convertido en el cascarón burocrático de las inquietudes científicas. En efecto, "no es la certidumbre ni la seguridad, sino la necesidad la que me ha impulsado a emprender este trabajo (...)” (Morin, 1993, p. 38). 
La división del trabajo y la producción en serie (Nieto Caraveo, 1991, p. 7) atentan contra la metodología interdisciplinaria, porque son obstáculos a la creación y la integración. Es así como puede vislumbrarse entonces cuál es la raíz filosófica de la disciplinarización o la militarización de la ciencia. El "caso metodológico” es la fuente de disrupción, en tanto se defiende de la normalización metodológica y la metodologización señalada. También dificulta la integración la división de la investigación entre quienes recolectan los datos y quienes los procesan y analizan, a los fines de combinar técnicas cualitativas y cuantitativas (Arroyo Menéndez, 2008 p. 198). Yendo más profundamente, retomando las críticas a la distinción entre ciencia básica y aplicada, a más especialización hay más cerramiento, ensimismamiento académico, a tal punto que se llega a hablar de innovación e incluso de emprendedurismo en la Universidad. No hay que olvidar que muchas veces la crítica se realiza desde el ámbito de la investigación científica, lo que requiere independencia respecto del mercado y la sociedad.

No puede hacerse un estudio de la relación entre las disciplinas, es decir, una filosofía de las disciplinas, sin incorporar a la mente del filósofo o cientista la idea de propiedad que atraviesa todas las manifestaciones humanas, desde las cosas con el derecho real de dominio, las personas con la exclusividad en el matrimonio y las ciencias divididas en disciplinas con respecto al conocimiento. ¿De qué Facultad sos?, se pregunta, como una manera de ubicar etiquetando a algún intelectual. Se trata de categorías disciplinares, como la que pude obtener de producción al estudiar el ingreso de Venezuela al MERCOSUR a propósito de tratar la transdisciplinariedad en la enseñanza del Derecho Internacional $\underline{15}$. Ahí vi que la producción es indispensable para el desarrollo económico, para la vida política del ciudadano y para el desarrollo humano del educando. Sin producción, en todos esos ámbitos, no hay individualidad y calidad en la existencia de las personas. Algo que puede obtenerse del marxismo es el comunismo científico $\stackrel{16}{ }$, es decir, la expulsión del derecho de propiedad con respecto al saber. Los conocimientos no son de propiedad de los científicos, ni se compartimentalizan en parcelas de conocimiento, sino que cualquiera, con los debidos cuidados, puede entrar en las disciplinas y salir de ellas. Esta utopía del conocimiento debería transformarse en hechos concretos a la hora de la admisión en los organismos científicos de proyectos encuadrados en problemas por áreas del saber en lugar de ser evaluados por comisiones constituidas por especialistas. No pienso en un abogado que se dedique a investigar sobre la filosofía de la matemática, lo que podría darse, sobre todo si se piensa en el trabajo en equipo, algo también raro, sino que los intercambios y las concesiones serían más posibles entre disciplinas pertenecientes a las ciencias o humanas y sociales por un lado, o exactas y naturales por el otro.

La filosofía integrativista, transdisciplinaria, compleja, plantea la idea de un comunismo científico, en el sentido de exponer la necesidad como título para el uso. No planteando dominios disciplinares, en donde los académicos serían los policías de los territorios intelectuales y los burócratas los encargados de impedir financiamientos, negar accesos si no se cuenta con el título, el diploma, que respalda el ingreso al campo. Nunca mejor ideada la noción de campo de Pierre Bourdieu, aplicada al mundo del conocimiento. El verdadero académico, el que tiene voluntad de romper con los prejuicios y lograr avances, es el que bucea en aguas que por el momento son desconocidas. Nadie es especialista hasta que comienza a serlo. La simplicidad también abreva en el hecho de no admitir la técnica del autodidacta. En determinado momento de la trayectoria intelectual, no es necesario demostrar "cartas credenciales" académicas para comenzar un estudio. Todo eso me hace decir que las mejores investigaciones pueden esperarse de aquellos que no están constreñidos por límites académicos, burocráticos y, sobre todo, estatales del saber $\frac{17}{}$.

Un comunista puede plantearme el hecho de la subsistencia de la división entre intelectuales y trabajadores manuales. Puedo decir que cada uno será mejor en tanto realice actividades del otro, para comprender lo que investiga, y por qué no, tomarse años sabáticos del academicismo para olvidar asfixias y cerramientos, y renovar aires. Eso es lo importante, la renovación, no el cambio o la división del trabajo. Es útil a la reflexión 
pensar en un investigador que va por su camino de descubrimiento en descubrimiento, sin detenerse en la ruta para tomar dominio del territorio (Resweber, 1981, p. 20).

\section{Contexto lógico del múltimétodos. Fundamentación y encuadre de la complejidad y la transdisciplinariedad}

Habiéndonos preguntado por la filosofía de la integración metodológica, cabe ahora abordar la lógica de la investigación desde una filosofía compleja, es decir, los distintos requisitos y exigencias de la complejidad y la transdisciplinariedad en términos metodológicos $\underline{\underline{18}}$.

En primer lugar, una aproximación no estrictamente técnica llama a combinar distintas metodologías al interior de un mismo diseño $\frac{19}{}$, es decir, a triangular, lo que implica que ya se están utilizando distintos métodos, sean éstos pertenecientes a la línea de investigación cualitativa o a la cuantitativa $\underline{20}$.

También se la conoce como “(...) la triangulación o utilización de distintos métodos en una misma investigación” (Cea D’Ancona, 1999, p. 47). Esto puede llamarse “integración” en sentido amplio, pero estrictamente sería una yuxtaposición metodológica, en donde simplemente se ponen juntas determinadas herramientas. "La yuxtaposición de especialistas (...) no produce la interdisciplinariedad (...)늘 (Cea D’Ancona, 1999, p. 93). Por ejemplo, se pueden utilizar datos como censos de población, informes de inspectores sanitarios, datos policiales, de organizaciones de beneficencia, conjuntamente con la observación directa en los propios barrios y las entrevistas en cuestión (Cea D’Ancona, 1999, p. 47). La importancia de la utilización de esta técnica radica en que se aumenta el grado de confianza en lo obtenido y se analiza la coincidencia o divergencia con los datos recolectados de las distintas fuentes (Cea D’Ancona, 1999, pp. 4849). Se trata de la utilización en un diseño de distintas herramientas en función de las necesidades y los tiempos, lo que verá el investigador en función del desarrollo de su investigación.

Se combinan distintos métodos de investigación en la descripción de un mismo objeto (Cea D’Ancona, 1999, p. 52). Por ejemplo, para analizar los factores que inciden en la comisión de la conducta delictiva de los adolescentes, combinar los datos estadísticos que proceden de la policía, el poder judicial y las instituciones penitenciarias, con los datos etnográficos, que se obtienen de la observación en lugares donde se cometen habitualmente actos de violencia y de las entrevistas a las víctimas y a los que cometen actos de violencia (Cea D’Ancona, 1999, p. 53).

Cuando se habla de las distintas interdisciplinas o de relaciones entre disciplinas, se señala que pueden establecerse afirmaciones de dos lenguajes con sus categorías y demandar luego que sean combinadas en subcategorías (Apostel, 1972, p. 155). Por ejemplo, tomar la investigación-acción, la observación y el análisis del discurso y, a la vez que se trabaja en el área respectiva a través de la acción del investigador, probar las hipótesis mientras se obtiene un diagnóstico del estado de situación de la población estudiada. Con la ayuda de las técnicas interpretativas de la hermenéutica, se podrán analizar los pensamientos expresados a la vez que tomar categorías a partir de ellos, con el lenguaje verbal, gestual y textual, en su caso. La diferencia con la triangulación se da en el hecho de que en la combinación las herramientas metodológicas funcionan no a los fines de la comprobación para obtener confiabilidad en el dato, sino para crear categorías (teóricas) y hacer funcionar los distintos pasos de la investigación.

Sobre todo en el marco de las investigaciones cualitativas, el aporte de las estrategias cuantitativas dará a la investigación aquello que necesitan los trabajos no positivistas: la posibilidad de encontrar unidades de medida y la experimentación (Piaget, 1972, p. 138). Aunque la combinación se da también a la inversa, cuando se hace hincapié en la metodología cualitativa como paso previo de la investigación. 
En los estudios en los que el propósito de la fase cualitativa es puramente (...) exploratoria, se aplica una pequeña investigación cualitativa antes de cerrarse el cuestionario. (...) [C]onsiste en unas pocas reuniones de grupo (...) complementadas o no con algunas entrevistas en profundidad. El propósito es obtener información que permita formular distintas hipótesis (...) ayudar a formular preguntas de acuerdo con la perspectiva y expresiones de los sujetos que van a ser interrogados y obtener los cierres (...) de las opciones de respuesta de las preguntas que se formulan en el diseño de

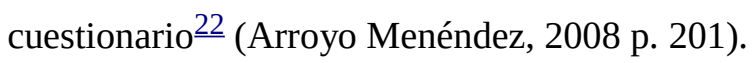

También puede pensarse el análisis cualitativo como etapa posterior y sustantiva en la medida que se interpreta algo que fue recolectado de la realidad en base a estrategias cuantitativas (Arroyo Menéndez, 2008, p. 204).

Aquí se apunta a combinar distintos modelos $\frac{23}{}$. Si tomáramos por caso a las entrevistas, el trabajo puede recibir también "números” provenientes de otras investigaciones que contextualicen lo investigado. La observación puede ser acompañada de, por ejemplo, escalas o esquemas que en cierta forma "midan" lo observado, o por datos estadísticos referidos al tema de investigación.

No solo se pueden combinar tradiciones de investigación, sino tipos. La integración metodológica plantea una gran problemática respecto de aquellas clasificaciones que distinguen entre investigaciones teóricas e investigaciones experimentales, en tanto éstas últimas eran las que tenían un contacto con la realidad. Frente a ideas que sugieren la necesidad de incorporar al saber teórico, los saberes experienciales y de acción, el debate se plantea respecto de la legitimidad de las investigaciones teóricas. ¿Investiga quien no toma contacto con la realidad cotidiana? Esta misma pregunta podría responderse señalando que esto es un problema teórico. Si no lo es, por ejemplo, todo trabajo o proyecto de investigación debería tener en cuenta estos dos niveles muchas veces olvidados: "Il y a un déséquilibre entre les savoirs théoriques qui sont prêts à être exprimés et les savoirs d'expérience qui ont rarement fait l'objet d'un travail de formalisation préalable” (Galvani, 2008, p. 7). A propósito de un ejemplo donde se plantea la investigación de la pobreza, "la confrontation de ce savoir expérientiel avec les savoirs théoriques des universitaires a permis aux militants d'aller encore plus loin dans l'explicitation느" (Galvani, 2005, p. 35). Aunque siempre la investigación teórica puede ser el trampolín desde el cual lanzarse a una investigación integral. Además, hay que tener en cuenta quiénes realizan las investigaciones y quiénes las financian, para ver sobre todo el propósito de los financistas, en tanto un objetivo de éstos puede ser su aplicación a la sociedad. En cuanto al saber de los voluntarios, ellos no necesitan teorizar sobre la necesidad de ayudar, simplemente lo hacen, porque "va de suyo” en ellos, pero “des séances de récits de pratiques et d'entretiens d'explicitation (...) ont permis de formaliser ces savoirs spécifiques ${ }^{25}$ ” (Galvani, 2005, p. 36). ¿Acaso ha habido un mejor marxista que Ernesto Guevara?, sobre todo si se lo compara con los jerarcas soviéticos y los marxistas de escritorio. Nicolescu ha planteado a la transdisciplinariedad como implicando tres aspectos: uno teorético, como metodología y generalidad, otro fenoménico, que conecta lo teórico con lo experimental y predice, y otro experimental, que aplica procedimientos que desarrollan experimentos $\underline{26}$ (Nicolescu, 2006).

Siguiendo esta línea de integración, la articulación en una investigación de los saberes-acción y los saberesvivenciales, permitirá poner en práctica las herramientas de la metodología cualitativa, lo que confirma la idea de la validez de estas herramientas no sólo por los argumentos derivados de la justificación “cualitativista” sino también por el hecho de la justificación "transdisciplinaria” de las investigaciones que tienen que integrar distintos niveles de investigación; así como niveles de realidad hay en el ser, en la vida. Lo que metodológicamente se traducirá en la necesidad de pensar en la combinación de objetivos de conocimiento y objetivos de transformación en los diseños de investigación $\underline{27}$. 
También se pueden integrar las distintas formas en que se llevan a cabo las herramientas metodológicas tradicionales en cada una de las disciplinas. Por ejemplo, recorrer investigaciones en cada uno de los campos disciplinares y ver cómo se emplea la entrevista; y, a partir de esas observaciones, articular aspectos positivos en la forma en que se lleva a cabo dicha metodología, tomando aportes de investigadores de las distintas ramas de la ciencia, incluso aunque pertenezcan a tradiciones metodológicas contrarias. Así, se observa un mismo objeto desde diferentes puntos de vista en función de la disciplina a la que se pertenece (Cea D’Ancona, 1999, pp. 49-50). Es lo que algunos llaman complementación: “([...) obtención de dos imágenes distintas, una más bien cuantitativa y otra cualitativa, de la realidad objeto de estudio” (Arroyo Menéndez, 2008, p. 205).

Profundizando en el análisis, hay articulación metodológica llamada "intrametodológica” cuando se repite la misma técnica metodológica en distintos momentos o situaciones $\underline{28}$ (Cea D’Ancona, 1999, p. 51). Aquí se trata de repetir. Sería el caso de la entrevista que se puede hacer en el marco de un grupo de discusión, a fin de que el investigador diseñe su hipótesis y futuras preguntas de una entrevista, y que luego de dicho diseño de la hipótesis, al avanzar la investigación, a la hora de la comprobación de aquella, realice las entrevistas del caso. También se puede dar la repetición en una misma etapa de la investigación, en tanto la entrevista se puede hacer a una misma persona en distintos momentos de su vida, si ello se relaciona con lo investigado, y se trata de una biografía, con lo cual se está ante el paso del tiempo en un individuo. Si se aplica la técnica de la historia de vida, será necesario pautar distintas reuniones con el entrevistado, porque aprehender su vida como elemento de estudio lleva un tiempo considerable.

La revisión bibliográfica o documental no solo se realiza para comprobar o verificar nuestras hipótesis, sino también en la etapa previa a la formulación de las mismas, para evitar distorsiones, distanciamientos y desenfoques del investigador, para hacer una investigación pertinente, de acuerdo a los intereses de los actores vinculados al campo que investigamos. Además, la documentación es vital para el elemento antecedentes, en donde recabamos el estado de la cuestión sobre un tema para no repetir los mismos hallazgos, volviendo a descubrir la pólvora. Incluso se suele plantear como una etapa previa a la formulación del problema.

Un matiz del intramétodo es aquel en donde se aplican distintas variantes de una misma técnica metodológica. La repetición es una variación formal, mientras que esta variación es material. Aquí se trata de variar. Por ejemplo, dentro de la estrategia documental, se acude a datos no publicados, datos publicados por organismos públicos o privados como informes o estadísticas, investigaciones publicadas en revistas o libros e investigaciones no publicadas (Cea D’Ancona, 1999, p. 222).

La investigación-acción es un ejemplo de articulación intrametodológica, ya que en una misma herramienta hay variación de pasos. Descripta la situación-problema, se efectúa un análisis crítico de los hechos y, reflexión bibliográfica mediante, se formularán las hipótesis que guiarán el curso de las acciones a implementar (Ministerio de Educación de la Nación, 2008, pp. 189-190). Más que una estrategia nueva, esta herramienta parece ser un marco metodológico en donde lo que se combina es la reflexión, la creación y la acción. Sabemos bien que “(...) le passage de la connaissance à l’action (...) exige une interdépendance des disciplines et engendre même des disciplines nouvelles $\underline{29}$ ” (Gass, 1972, p. 7). Lo novedoso se presenta al proponer el plan, que implica dar cuentas de: la idea general, los factores a cambiar y el curso de las acciones, las negociaciones necesarias, los recursos estimados, los aspectos éticos y la comunicación de la información. Luego, para poner a prueba la hipótesis, son necesarias las técnicas metodológicas del caso (Ministerio de Educación de la Nación, 2008, p. 190). 
La implementación de la I.A. [investigación-acción] supone cierto tipo de condicionantes tales como: las características institucionales, los sujetos que participarán, el momento y la modalidad de intervención, los objetivos, el grado de información con que se cuenta desde el inicio, cómo se articulan los encuentros del grupo y cómo se produce la comunicación al interior del mismo. Todo ello, supone acuerdos previos y el principal: la búsqueda colectiva de soluciones (Ministerio de Educación de la Nación, 2008, p. 190).

Una integración "intermetodológica” puede darse a través de la creación de una nueva herramienta metodológica a partir de dos previamente existentes (v. Nieto Caraveo, 1991, p. 7), por ejemplo. Esto se daría en el caso de los "grupos focales", donde se toman elementos de las entrevistas y otros elementos de los “informantes claves". No es ni una ni otra metodología, ya que no son personas que abren la puerta a fuentes de información, ni se plantean cuestiones para responder, sino que se trata de la manera en que el grupo reacciona a distintos planteamientos, mediante una moderación que guía. Aquí se trata de crear. Según Piaget, la combinación sería el producto del encuentro de estructuras semejantes $\underline{30}$ (Piaget, 1972, p. 143) entre ambas herramientas, en tanto los grupos comparten con los informantes el hecho del conocimiento experiencial o vivencial del tema a investigar, y a ambos se les hacen entrevistas con cuestionarios y diálogos. Aquí se ve a la integración, en sentido estricto, como aquello que puede incluir aspectos metodológicos sin repetirlos en su estado original $\underline{31}$ (Follari, 2007).

Como la investigación es una acción que se desarrolla siempre en casos concretos, producto de diseños que se implementan y avanzan, a propósito del reconocimiento actual de la incertidumbre en las ciencias, hay que dejar un espacio para ella que, traducido al ámbito metodológico, significa que el propio investigador sea

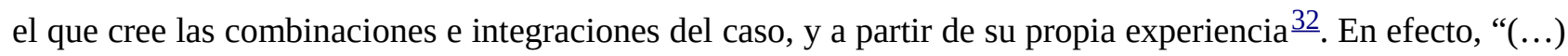
una investigación (...) postmoderna, deberá constituir una autorización en donde sus peculiares fundamentos, deberían emerger en el curso de la búsqueda, más bien que estar predeterminados en la forma de teorías ligadas a la disciplina, métodos y escuelas de pensamiento” (Mourad, 1997, p. 13). Con esta idea coincide Morin: "hoy no se puede partir más que con la incertidumbre, incluida la incertidumbre sobre la duda. Hoy tiene que ser metódicamente puesto en duda el principio mismo del método cartesiano (...)” (Morin, 1993, p. 28). Siguiendo a Hegel, el reduccionismo científico engendra las causas de su propia negación, y en este sentido es posible tomar ventajas de lo considerado peyorativo. Así, “(...) al menos podemos disponer de un anti-método en el que ignorancia, incertidumbre, confusión se convierten en virtudes” (Morin, 1993, p. 29).

Esto guarda estrecha relación con el llamado método de la "investigación-acción”. Esta estrategia de la investigación denominada cualitativa encierra una polémica en tanto apunta no sólo a producir conocimiento sino a generar un cambio. Se trata de “(...) una estrategia especialmente adecuada para introducir cambios y mejoramientos de la práctica” (Ministerio de Educación de la Nación, 2008, p. 185). El objetivo de la estrategia no es producir conocimiento básico (Ministerio de Educación de la Nación, 2008, p. 187). Se da entonces el debate que tiene su génesis en el concepto de filosofía, sobre todo cuando algunos la consideran como una actitud contemplativa dirigida a reflexionar sobre los profundos y fundamentales problemas del ser. Mientras que en un extremo se la entiende como "la alegría de entender” según Spinoza (Salas, 2004, p. 29), por el otro lado se la considera como un método para lograr cambios, un "arma para la revolución” (Althusser, 1968). De esta forma podrían integrarse las dos visiones que hay sobre la filosofía, que en este caso se trasladarían al campo metodológico. Es decir, debería plantearse un pensar para hacer y un hacer para pensar en ocasión de la investigación. En otras palabras, pensar la acción y actuar lo pensado, rememorando a Kant. "El entendimiento no puede percibir y los sentidos no pueden pensar cosa alguna. Solamente cuando se unen, resulta el conocimiento” (Kant, 2006, p. 226). Metodológicamente se trataría de llevar a cabo transformaciones para analizar su impacto, lo que ya sería propio de la técnica, y de programar 
contemplaciones para conocer. Kuhn habla sobre el conocimiento tácito, “(...) que se obtiene practicando la ciencia, no adquiriendo reglas para practicarla” (Kuhn, 1996, p. 292). Así se entiende entonces cómo la modificación de los escenarios objeto de nuestra investigación recibirían el impacto de nuestro hacer y la recepción, la absorción de dicho impacto sería materia de la reflexión.

\section{La transdisciplinariedad ${ }^{33}$ y la complejidad como técnicas metodológicas}

Cabe preguntarse cómo podría un investigador, trabajando individualmente, hacer interdisciplina/transdisciplinariedad, sin constituir un equipo de investigación formado por profesionales de distintas disciplinas. Hay que tener en cuenta que el mero hecho de que hayan diversos profesionales no garantiza que haya interdisciplina. Es decir, nos preguntaremos por la transdisciplinariedad como herramienta de investigación. ¿Cuándo el investigador hace transdisciplinariedad? La respuesta básica, fundamental a esa pregunta, consiste en señalar que no hay que cortar o separar los conocimientos de los conocedores, es decir: los conocimientos no son más separados del sujeto, sino que forman parte de él (Demol, 2003, p. 17). De ahí la necesidad de evitar encasillar a un investigador científico en una disciplina y, menos aún, en una rama de la disciplina. Al contrario, mientras más se "pasee” por la (teoría de la) ciencia y por las ciencias mayor comprensión tendrá del ser humano.

Una forma de instrumentalizar la “filosofía interdisciplinar” puede comenzar con la utilización del lenguaje proveniente de otras disciplinas, de manera que puede constituirse este acto en una primera forma de "hacer pie” en la disciplina para luego, eventualmente, continuar con los intercambios. Pueden citarse como ejemplos lo sustentable, nacido en la ciencia ambiental, y la información nacida en la cibernética y que puede complementarse con la homónima de las ciencias de la comunicación. Puedo tomar ideas que desarrollé al aplicar la transdisciplinariedad en el ámbito de la enseñanza del Derecho Internacional a través de lo que llamé "consignas transdisciplinares":

¿cuáles serían los temas que considera vinculados a la temática en estudio pero que no se considera apto para tratar?, ¿conoce libros vinculados a la temática pero no relacionados directamente con el Derecho?, ¿conoce grupos o foros en los que se discuta la temática encarada?, ¿qué le preguntaría la Filosofía a su tema $\stackrel{34}{\text { ? }}$, ¿podría hacer un informe o brindar sus opiniones o críticas acerca de su asistencia a un encuentro académico vinculado a la temática en estudio?, ¿qué contribuciones relevantes podrían trasladarse a las disciplinas?, ¿hay presupuestos, puntos de vista, lenguajes compartidos? Piaget se preguntaría por los intercambios que serían posibles, como los desplazamientos, las proyecciones, las afinidades, similitudes. ¿Son los detalles en algún dominio susceptibles de aclarar otro? Como la didáctica se plantea transdisciplinar y esta metodología incluye al sujeto, hay que hacer hincapié en él, por ejemplo, estudiando la obra y la vida de algunas figuras célebres, a las cuales se comprenderá y criticará. (Galati, 2013, pp. 321-322).

Como señalamos, la trandisciplina surge con Piaget en 1970 y la transdisciplinariedad con Nicolescu en 1985, aunque algunos señalen que introdujeron la idea en 1987 $\underline{35}$ (Mittelstrass, 2011, p. 329). Si bien esta es una orientación o una actitud, como la llama Morin aún a riesgo de desnaturalizarla, cabe sistematizar, provisionalmente, sus ideas y aportes, a fin de brindar herramientas, al investigador en este caso, para que, valiéndose de sus aportes, pueda mejorar sus investigaciones. Al tratarse de la transdisciplinariedad, la salvedad consistirá en mantener siempre las fronteras libres entre las disciplinas, y entonces combinaré la idea de sistematizar y reflexionar, la de la ciencia y la filosofía, en última instancia. "El problema fundamental es, pues, restablecer y cuestionar lo que ha desaparecido con la disociación: esta relación misma” (Morin, 1993, p. 22). 
A la hora de sistematizar los aportes de la complejidad y la transdisciplinariedad en el ámbito de la metodología de la investigación científica, cabe dividir a la investigación en etapas, que básicamente son dos: la de la planificación de la investigación y la de la investigación propiamente dicha. Mientras que el diseño es el producto académico que planifica, es decir, "supone una actividad destinada a establecer el mayor grado de coherencia posible entre el producto que se quiere obtener, con las actividades que se deberán realizar, y los fines que se espera alcanzar” (Samaja, 2004 48). Analizaremos el diseño de una investigación y las etapas previas a él desde la perspectiva compleja y transdisciplinaria.

1. Estrategias asistemáticas. Son tales porque se trata de acciones no teorizadas ni categorizadas, ni a su vez planificadas o esquematizadas. Pueden señalarse algunas actitudes o estrategias investigativas que serían transdisciplinarias, es decir, no localizables en disciplina alguna y que no responden a una regla: a) lectura de textos de otras disciplinas, vinculadas al tema de estudio; b) auxilio de profesionales de otras disciplinas, a través de charlas con informantes clave, relectura y aportes de esos profesionales especializados; c) entrevistas a personajes que no serán los de la profesión del investigador y que podrán darle perspectivas, ideas y datos vinculados a la temática de investigación; d) integración de un proyecto de investigación afín a la temática, y en donde las actividades que a raíz de él se realicen incorporen aportes pertinentes; e) encuentros académicos, libros de autoría colectiva, charlas informales, etc. A través de un trabajo más fino e internalizado, la utilización de términos, prácticas o, en el mejor de los casos, marcos teóricos distintos al suyo, podrá el investigador sumergirse en modelos teóricos provenientes de otras disciplinas, pero que seguramente tienen analogías con su disciplina. Esto permitirá variar formas de trabajo y concepciones, que son en definitiva los aportes últimos del trabajo multidisciplinario. He aquí una aproximación a la metodología transdisciplinaria, que luego puede sistematizarse y mejorarse con la trayectoria y experiencia en investigación. No me parece desacertado que algunos autores piensen estas aproximaciones como pertenecientes a la interdisciplinariedad, en tanto cooperaciones concretas de duración finita, mientras que la transdisciplinariedad implicaría una cooperación duradera y sistemática que cambiará la perspectiva de las temáticas y las disciplinas (Mittelstrass, 2011, p. 331). Así se da en la teoría trialista del mundo jurídico, para la cual el Derecho es más que ley, en tanto está compuesto por las dimensiones social, normológica y axiológica. El abordaje transdisciplinario está incorporado en la visión jurídica tridimensional producto de considerar al objeto jurídico como complejo $\underline{36}$.

2. Estrategias sistemáticas. El abordaje metodológico transdisciplinario implica ya no tener a la transdisciplinariedad como programa, como utopía o idea a alcanzar, sino como parte integral del proceso de investigación, como diseño, y posteriormente en la investigación propiamente dicha. Esto implica incorporar a la transdisciplinariedad en el diseño, en cada uno de sus elementos; en donde cada uno se entenderá en relación con los otros.

Concebir la circularidad es (...) abrir la posibilidad de un método que, al hacer interacturar los términos que se remiten unos a otros, se haría productivo, a través de estos procesos y cambios, de un conocimiento complejo que comporte su propia reflexividad (Morin, 1993, p. 32).

Habrá transdisciplinariedad si el tema comienza por abarcar temáticas que den lugar a la participación de distintas disciplinas. Hay que "(...) aprender a articular los puntos de vista disjuntos del saber en un ciclo activo” (Morin, 1993, p. 32). Piénsese en la salud y los comités de bioética hospitalarios, que se integran con distintas profesiones precisamente porque la salud no sólo puede responderse y preguntarse desde la Medicina. Los contenidos disciplinares verticales aislados devienen inoperantes para la comprensión de fenómenos complejos (Demol, 2003, p. 14). No se puede hablar de clases de normas, de tipos de interpretación, sin incluir en estos temas y otros, por ejemplo, aspectos sociales y valorativos. No se puede hablar del agua en sus compuestos químicos, sin los aspectos políticos que la tratan como un bien común o 
una mercancía. Si bien el recorte a los fines de la investigación puede estar dado por uno u otro aspecto, el tratamiento complejo es inevitable.

Proponerse un tratamiento transdisciplinar y complejo implica, como señala Morin, luchar contra la fuerza infernal y casi infinita de la burocracia científica cuya misión es imponer la especialidad en el mundo académico. Así, “(...) el investigador ve cómo se le ofrece la posesión exclusiva de un fragmento del puzle, cuya visión global debe escapar a todos y a cada uno” (Morin, 1993, p. 25). No hay que confundir el recorte del tema con el aislamiento del tema. Cunde la hiperespecialización, no solo aislándose la ciencia de otras, sino en el interior de ella misma. Morin lo señala respecto de la Física, separada en micro y macro (cosmo) física (Morin, 1993, p. 26), pero también se ve en el Derecho, con las ramas tradicionales que vagabundean separadas en congresos e institutos. "Como el hombre, el mundo está dislocado entre las ciencias, desmigajado entre las disciplinas, pulverizado en informaciones” (Morin, 1993, p. 26).

Habrá transdisciplinariedad si el problema es recortado, como lo exige la Metodología, lo que no significa que no toque distintas disciplinas, aunque recortadamente. Si se elige a la salud como tema y se pretende hablar sobre la articulación de los profesionales en torno al comité de ética, se tomarán aportes de cada una de las profesiones y disciplinas en torno a ese tema en común, es decir, cómo articular los aportes. "Las formas de gobierno" pueden ser abordadas por la Política, el Derecho, la Sociología y la Filosofía, por ejemplo, porque allí se hablará de la distribución del poder, del papel de la justicia, la reacción de la comunidad frente al poder, y su naturaleza, vinculándolo al hombre, donde también la Antropología tendrá qué decir. El ambiente, la energía, tampoco son tratables solamente de manera científica (Mittelstrass, 2011, p. 331). Ampliando la profundidad filosófica, todos los problemas pueden ser tratados multidisciplinarmente. Si se piensa en uno muy disciplinar, como alguno relativo a la Matemática, también un cálculo puede hablar acerca de su historia, sus aplicaciones concretas, etc.

Así como la transdisciplinariedad se puede aplicar a nivel científico, por su concepción que habla de distintos niveles de realidad, un nivel de realidad a tomar puede ser el científico y otros pueden ser el vulgar, el filosófico, el religioso y el artístico. Es común en la tradición científica delimitar, y una manera de hacerlo puede ser no solamente desde el punto de vista temático, sino también desde el punto de vista disciplinar, si seguimos en la ciencia, o desde el punto de vista transdisciplinar, si la investigación se va a enfocar, por ejemplo, desde el arte. También el recorte puede estar dado por lo que queremos conocer, o por lo que queremos transformar. Puede ser que de la transformación que se opere en el campo devengan conocimientos útiles a la ciencia. Cabe aquí observar lo científico de la técnica, vinculado a la investigación-acción.

En el momento de mayor creatividad y espontaneidad que nos demanda la investigación, podemos pedir el auxilio de la Psicología a fin de bucear en textos que nos permitan sondear la manera de dar a luz nuestros deseos, que son los que motivarán desde lo profundo nuestras ganas de investigar, y formular entonces las primeras preguntas a partir de las cuales seleccionaremos el "problema”. De ahí que pueden señalarse artículos interesantes como "Acerca del humor, la creatividad y el juego" de Daniel Delguy, o libros como Educar la intuición de Robin Hogarth. Gregorio Klimovsky ha compilado estrategias vinculadas a la creatividad en la ciencia 37 . Edgar Morin plantea "El derecho a la reflexión” y Pierre Bourdieu señala "La ruptura”, elementos indispensables para disparar problemas y cuestionar supuestos, en tanto la primerísima parte de un proyecto de investigación integra filosofía y ciencia. Al final también se plantea al investigador una nueva integración de la ciencia y la filosofía, en tanto ha sido científico, aunque debe reflexionar sobre la manera en que investigó, y de esta forma, con la "meta-reflexión metodológica”, similar a lo que ocurre con el estudiante que emplea estrategias metacognitivas, pensará la manera en que investigó para trasladar formas de pesquisa a futuras investigaciones. "Nos servimos de nuestra estructura de pensamiento para pensar. Necesitaremos también servirnos de nuestro pensamiento para repensar nuestra estructura de 
pensamiento" (Morin, 1993, p. 35). Y el resto de la comunidad científica podrá aprovechar también dichas reflexiones. No cabe asimilar este trabajo con la literatura metodológica, en tanto el autosocioanálisis metodológico es una labor artesanal propia del trabajo del investigador, con toda la riqueza del caso. Aquí se hablará de estrategias metametodológicas. Se dice que nuestras intuiciones, esas decisiones que tomamos “sin pensar", derivan de nuestra experiencia (Hogarth, 2002, p. 13), por lo que será una tarea de introspección inevitable bucear en nuestra historia personal a fin de tomar un primer contacto con nuestro tema de investigación. De esta forma el investigador deberá buscar “indicios” y luego sopesarlos a fin de formar la decisión a tomar en el diseño. Se integra la Psicología a la Metodología y seguramente se podrán combinar estrategias premetodológicas para encontrar un tema de investigación, lo que conformaría las "tratativas de las ideas".

Cabe preguntarse cuál es el lugar del investigador en la investigación. En efecto, “(...) el observador que observa, el espíritu que piensa y concibe, son indisociables de una cultura y, por tanto, de una sociedad hic et nunc" (Morin, 1993, p. 23). Siempre se escucha la pregunta acerca de escribir en primera persona del singular o la primera persona del plural. La última opción encierra la idea de la objetividad. La primera opción acompaña la idea de la responsabilidad del científico, que la ciencia clásica expulsa a la técnica. "No es la ciencia anónima la que se expresa por mi boca 3 "” (Morin, 1993, p. 38). He dicho que cuando nos basamos en ideas compartidas, la obligación es utilizar el plural, porque compartimos los antecedentes que heredamos y que asimilamos.

La dirección de la investigación es un tema fundamental, porque el director es quien guía al tesista, lo que implica sugerirle y llevarlo por caminos que puedan conducirlo al éxito. En la práctica hay directores más intervencionistas y otros más abstencionistas. La idea no consiste en imponer, sino en dar a luz los verdaderos deseos de investigación del tesista. Por ejemplo, de la lectura de sus esbozos, puede surgir el verdadero tema de interés. La codirección puede ser una buena ocasión para incorporar prácticamente la interdisciplinariedad, de manera de poder lograr el equipo en el acompañamiento, sabiendo ambos directores de la existencia del otro y trabajando siempre en el interés del tesista.

Coherentemente, la hipótesis deberá ser transdisciplinar, es decir, deberá incorporar articuladamente aportes de las distintas disciplinas. El investigador deberá hacer el esfuerzo de sintetizar sobre la base de la detección de elementos en común de todos los aportes, a fin de ensayar una respuesta provisoria que los incorpore.

El concepto idea rectora es una combinación de la hipótesis con la necesidad de flexibilizar la investigación a medida que la misma se va desarrollando. Así como ocurre en la Educación, en donde el docente plantea una planificación y luego su alumnado la modifica por sus características propias. Lo propio ocurre con la idea rectora que debe amoldar la idea del investigador a la cambiante e influyente realidad. Se "integran" aspectos "duros” de la hipótesis, que guía la investigación con una idea preconcebida o intuición que tenemos, con la flexibilidad mencionada. No hay una observación pasiva como la concebían los inductivistas, ya que nosotros somos quienes preguntamos a la realidad y la "hacemos hablar". No por ser flexible dicha idea rectora dejará de ser precisa, dejará de ser una tesis que plantea una solución a un problema y, como tal, delimitada temporal, espacial y personalmente, para que nuestra investigación sea recortada, acotada, posible.

La integración se puede dar en el elemento hipótesis/idea rectora, de manera que una categoría apta para articular ambas ideas, dialógicamente, sea la de respuesta. La dialógica moriniana permite precisamente que concurran antagónicamente dichos aspectos de la respuesta, en tanto habrá momentos de hipótesis y momentos de idea rectora, según las necesidades. Cabe aquí relacionar la dialógica con la oscilación. No puede romperse la circularidad entre las dos ideas y tratar de reducir la investigación a uno de los términos, sea eligiendo la hipótesis o la idea rectora. No cabe aislar, sino concebir la unión (Morin, 1993, p. 31). La 
amplitud del término permite tomar las ventajas de ambos elementos pertenecientes a tradiciones de investigación tan distintas y complementarlas coordinadamente en un mismo ítem, a la sazón integrado. "L'épistémologie transdisciplinaire permet ici de mieux appréhender les relations possibles entre approches contradictoires et de pouvoir les articuler au lieu de les opposer $\underline{39}$ ”, (Paul, 2005, p. 9). También se señala que la investigación interdisciplinaria es la que permite, en las personas más creativas, la asociación de ideas inesperadas (Apostel, 1972, p. 165), que a la sazón permitirán proponer nuevas soluciones.

Los antecedentes de la investigación se traducirán en una sección bibliográfica general, referida al tema, y secciones bibliográficas especiales que se nutrirán de las disciplinas que aporten al problema planteado. Nótese que el investigador, en este elemento, a la hora de completarlo, hará “carne” la transdisciplinariedad, en tanto deberá ir a un catálogo general, pero también a cada una de las bibliotecas que componen la Universidad en la cual está radicado su proyecto $\underline{40}$. Además, ir al lugar físico de dichas bibliotecas implicará la oportunidad de tomar contacto con el espacio que significa el lugar de encuentro de los especialistas de la unidad académica, contacto eventual con informantes clave de la misma, charla con autoridades, acceso a información relevante, por ejemplo sobre seminarios, congresos, etc. Cuán interesante suele ser observar los afiches y carteles que solo están en los lugares académicos con los cuales toma contacto nuestro tema.

Las herramientas metodológicas utilizadas en la Historia, como disciplina científica, nos permitirán en nuestra investigación, y preliminarmente en un diseño de investigación, bucear en los antecedentes de nuestro objeto, de manera de analizar los estudios anteriores en los cuales basarnos y que no deberemos repetir. Esto es fundamental para todo lo relativo al elemento del diseño llamado antecedentes. Hay allí estrategias derivadas de la búsqueda documental que sería interesante analizar para acceder a bibliografía confiable. Es una manera en que el investigador en soledad puede investigar para hacer interdisciplina, en tanto toma contacto con otra disciplina, en este caso la Historia.

Los objetivos específicos significarán una trayectoria disciplinaria de resultados a esperar y que satisfagan las exigencias de todas las disciplinas vinculadas al tema de investigación. Muchos han sido los objetivos específicos que recorren las dimensiones trialistas, y hay objetivos de la dimensión sociológica, de la dimensión normológica y de la dimensión dikelógica, relacionando un elemento -los objetivos- con otro: el marco teórico. Se piden aquí tipos de productos y sus utilidades concretas (Saltalamacchia, 2005). El objetivo general debe satisfacer a todas las disciplinas involucradas por igual y en particular a la ciencia o la filosofía de la ciencia. Indirectamente contribuirá a la transdisciplinariedad, como Teoría General/Provisoria de la Ciencia. Probablemente, el objetivo general será útil a la Epistemología, en tanto la investigación sea transdisciplinaria. Algunas veces se ha criticado o señalado que la Transdisciplinariedad no es una teoría de la ciencia, y es cierto si se ve a ésta como un recetario metodológico unificador. Así, “(...) la teoría unitaria (...) obedece a una sobresimplificación reductora enganchando todo el universo a una sola fórmula lógica” (Morin, 1993, p. 28). En primer lugar, la Transdisciplinariedad reconoce niveles de realidad, lo que implica reconocer niveles científicos, y en este sentido las Ciencias Sociales y las Ciencias Naturales son dos ámbitos de estudios con especificidades, en este caso metodológicas. Esto no obsta a que pueda haber intercambios entre dichos ámbitos. De hecho la importancia del investigador comenzó a aceptarse cuando en el ámbito de la Física Cuántica se "confirmó” que el sujeto perturba la labor de medición y se reconocieron también las “incertidumbres $\underline{41}$ ".

Los objetivos específicos serán de las disciplinas involucradas. El objetivo será transdisciplinario si apunta a un resultado que satisfaga a la problemática. Otra relación que puede establecerse se da valiéndonos de la terminología de Sautu, que dice que la teoría social influye en la confección del “objetivo general”, mientras que la teoría sustantiva se involucra en el desarrollo de los objetivos específicos. Unos, los específicos, se derivan de otros, los generales, así como la teoría sustantiva es una derivación filosófica de la teoría general, 
las cuales a su vez derivan del paradigma (Sautu, 2005, pp. 48-49).

El marco teórico transdisciplinario apunta a una convivencia de ideas no necesariamente compatibles. Morin muestra los distintos paradigmas que han sido reductores: “(...) el conocimiento que une un espíritu y un objeto es reducido, bien al objeto físico (empirismo), bien al espíritu humano (idealismo), bien a la realidad social (sociologismo)" (Morin, 1993, p. 31). Esto guarda relación con los otros tantos paradigmas que señala en otra oportunidad: “(...) el Orden en las concepciones deterministas, la Materia en las concepciones materialistas, el Espíritu en las concepciones espiritualistas, la Estructura en las concepciones estructuralistas (...)” (Morin, 1999, p. 8). En el caso del trialismo, un marco teórico para el Derecho, hay una convivencia de aportes sociológicos, normológicos y dikelógicos. Cada dimensión representa una corriente jurídica: la dimensión sociológica desnuda la más cruda realidad como la estudian los autores realistas y luego los críticos en sus vertientes francesa y alemana, y los Critical Legal Studies” con Duncan Kennedy. Cabe incluir aquí al Uso Alternativo del Derecho. La dimensión normológica tributa al Positivismo Jurídico con todas sus variantes: incluyente, excluyente, la Escuela Analítica. Y la dimensión dikelógica presenta afinidades con el Jusnaturalismo o el Neoconstitucionalismo, también conocidas como posturas "no positivistas”. La ventaja de la Teoría Trialista se da por la coordinación sistemática de los aportes de las tres dimensiones en categorías, como lo ha pensado Goldschmidt, y previéndose relaciones e interrelaciones en y entre las dimensiones $\frac{42}{}$. Será tarea de los investigadores transdisciplinarios descubrir integraciones y crear articulaciones, en una misma disciplina, de lugares teóricos provenientes de distintas ciencias (v. Mittelstrass, 2011, p. 330). Los comités de bioética en todas sus versiones reclaman a las Ciencias Médicas la llamada humanización de la Medicina. En mi caso, he incorporado a las investigaciones realizadas aportes de Morin $\underline{43}$, Foucault $\underline{44}$, Bourdieu $\stackrel{45}{ }$. Las clasificaciones disciplinares son el resultado de las variancias históricas (Mittelstrass, 2011, p. 330), lo que equivale a decir que nada hay "natural” o "en sí” en el campo metodológico, que abreva del campo epistemológico. Nótese por ejemplo la historia del tratamiento del calor, en un principio como un movimiento interior de la materia y entonces estudiado por la Física, luego como una cuestión calórica y estudiado por la Química, para finalmente, en la teoría kinética, ser estudiado nuevamente por la Física. En efecto, “(...) not (just) the objects define the discipline, but our manner of dealing with them in theory $\underline{46}$ ” (Mittelstrass, 2011, p. 330). Y haciendo énfasis en la manera de investigar, podemos adecuar nuestro espíritu a la hora de encontrar una paradoja, que surge a propósito del marco teórico pero que puede surgir en cualquier elemento del diseño. Frente a un antagonismo podemos reaccionar viendo la puerta a una relación (Morin, 1993, p. 31) en lugar de un cerrojo que selle un aislamiento.

(...) une ouverture percée dans un mur forme un passage entre deux pièces ; ce vide crée le lien entre deux espaces) ; au même titre que la rupture qui est également une liaison. (...) la rupture construit un nouveau lien. Tel le marginal (...) sa rupture sociale est l'expression de ce qui le relie à la société. L’absence de lien peut lier ; l'absence implique la présence ; le non-lien est un lien ${ }^{47}$ (Buguet, 2003, p. 141).

El multimétodos no necesariamente implica que el investigador ciña su tarea a un único marco teórico. "El quehacer interdisciplinario está basado, tanto en la elaboración de un marco conceptual común que permita la articulación de ciencias disímiles, como el desarrollo de una práctica convergente” (García, 2006, p. 67). De hecho, basarse en distintos sistemas de ideas le permitirá aplicar distintas metodologías y crear otras nuevas. Por ejemplo, autores como Pierre Bourdieu y Michel Foucault no son incompatibles, a pesar de que no se citan (Zicavo, 2013). En definitiva, “(...) es posible entre teorías tan diversas, lograr una convivencia coherente al interior de una trama teórica compleja, no obstante provenir de racionalidades de diversa índole (...)” (Pozzoli, 2011, p. 32).

Si pudiéramos captar la "filosofía” de nuestro marco teórico, que implica profundizar en los aspectos, 
conceptos y variables de nuestra pregunta e hipótesis o idea rectora, seguramente podríamos abrevar en un sistema de ideas dado a fin de localizar herramientas metodológicas pertenecientes a él que nos puedan ayudar. Es importante para esta tarea psicoanalizar nuestra pregunta y nuestra respuesta, en el sentido de percibir por qué usamos las palabras que empleamos, de dónde las obtenemos, y si se relacionan con lo que queremos decir. Sobre todo en la "manera" en que dicho sistema de ideas encara la investigación. Si bien puede no presentarse directa y explícitamente una herramienta metodológica, la tradición teórica puede brindarnos consejos, sugerencias u otros comentarios que podremos incorporar al campo metodológico. Son muy útiles las lecturas de las "bibliografías" de los artículos, y a veces mucho más que los contenidos mismos.

Metodológicamente, la transdisciplinariedad se traducirá en la utilización de las herramientas necesarias para cubrir el abordaje del objeto/proceso de estudio, lo que puede significar incorporar herramientas de distintas disciplinas. También puede implicar crear las herramientas necesarias para la investigación en curso y que el investigador deberá pensar precisamente en función de sus necesidades. En efecto, “(...) it [interdisciplinarity] undoes disciplinary rigidities whenever these obstruct the formation of problems and corresponding research-based actions (...) ${ }^{48}$ ”, (Mittelstrass, 2011, p. 331). La triangulación es inexorable, por la creciente incertidumbre y cuestionamientos al conocimiento científico. Cada nivel de realidad involucrado en la investigación necesitará de una metodología propia. Piénsese en los niveles psicológicos, biológicos, espirituales, políticos, económicos; o tal vez en los materiales e ideales, según el recorte clasificatorio que haga el investigador.

Cabe preguntarse qué puede pensarse de la vecindad disciplinar en pos de tratar la transdisciplinariedad. Pueden haber proximidades que se traduzcan en mayores intercambios y mayores entendimientos, en tanto la visión lógica y abstracta derivada de muchas disciplinas englobadas en las llamadas ciencias duras o exactas como la Física, la Química, la Biología, la Matemática, conlleva una manera de entender el mundo que puede remontarse a Parménides y la estabilidad del ser, y que sigue en pensadores como Pitágoras, Platón, Galileo, pasando por Descartes y culminando en el Círculo de Viena que pregonaba la unidad de la ciencia en el método matemático y experimental, claramente visible en epistemólogos como Mario Bunge $\underline{49}$. Así como la barrera idiomática impulsa al aprendizaje de los idiomas, que se traduce en riqueza conceptual, lo propio se da si el investigador se esfuerza por entender a sus vecinos y al resto de los habitantes no próximos. Así como el lenguaje condiciona el pensamiento y lo que conocemos, las distintas ciencias, con sus términos y lenguajes, hacen lo propio.

La transdisciplinariedad plantea un problema epistemológico, en tanto si se quiebran las barreras disciplinares y se abre el campo de estudio al ingreso de otros conocimientos, hay que preguntarse por su pertinencia a la hora de la admisión, lo que conlleva una evaluación acerca de la cientificidad. Lo que algunos niegan rotundamente, puede problematizarse, como señalar que la transdisciplinariedad es una guía para la percepción de problemas, pero no se solidifica en formas teóricas, como un método $\underline{50}$ (Mittelstrass, 2011, p. 332). Si el espíritu de la transdisciplinariedad es ser una actitud desviante, que no se coloquen entonces límites a dicha actitud. La filosofía de la disciplina es justamente el límite, el cerramiento. Otro problema de esta naturaleza se da cuando se señala que hay que adquirir competencias disciplinarias como una condición para el trabajo transdisciplinario (Mittelstrass, 2011, p. 332). Si se señala que la historia, el devenir de los investigadores, en alguna medida construye las unidades de análisis de la ciencia, es obvio concluir que lo que está antes o después es también una cuestión de hábito. Lo que parece loable es señalar que cuando los límites científicos se mueven, lo propio debe ocurrir con las estructuras burocráticas (Mittelstrass, 2011, p. 333). Así, “(...) en el seno de la Institución científica reina la más anticientífica de las ilusiones: considerar como absolutos y eternos los caracteres de la ciencia que son los más dependientes de la organización tecnoburocrática de la sociedad” (Morin, 1993, p. 30). Si se cuestiona enérgicamente la 
especialización y la disciplinariedad, los organismos científicos no deben valorar positivamente la especialización de los investigadores. Con un buen proyecto y justificadamente, deben admitirse como loables los saltos disciplinares e intradisciplinares, sobre todo en las investigaciones avaladas con trayectorias o que impliquen a directores o maestros con trayectoria. Lo que en términos trialistas significa que la planificación está ahogando la ejemplaridad -espontaneidad-, es decir, que las formas burocráticas de la ciencia no se corresponden con las vanguardias científicas. "This order of science is becoming

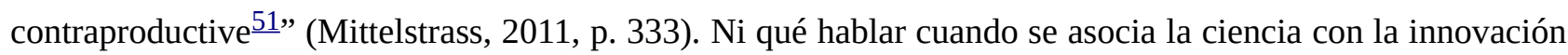
o la llamada ciencia aplicada, haciéndola depender de la industria o el mercado $\underline{52}$. Por ello, investigar compleja y transdisciplinarmente implica una ruptura: "desde un auténtico diálogo de saberes, pasando por la elaboración de nuevos instrumentales metódicos, hasta la instauración de modalidades inéditas de gestión del conocimiento” (Lanz, 2010, p. 16).

3. La transdisciplinariedad y la complejidad en la investigación propiamente dicha tienen distintos despliegues. El principio recursivo de la complejidad nos indicaría que, sin dejar de separar para un mejor análisis el diseño de la investigación, de la investigación propiamente dicha, lo trabajado para el diseño puede utilizarse en la investigación.

El principio recursivo significa que debemos concebir los procesos generadores o regeneradores como bucles productivos ininterrumpidos en los que cada momento, componente o instancia del proceso es a un tiempo producto y productor de los demás momentos, componentes o instancias (Morin, 2003, p. 25).

Por ejemplo, cuando el tesista redacta su diseño, en cada uno de los elementos, parte de dicha redacción puede aprovecharse para la investigación. El problema será colocado y ampliado en la "introducción”, para motivar al público a la lectura del trabajo. La idea rectora será continuamente fundamentada, cuestionada, y elaborada a lo largo del trabajo y constituirá la guía del tesista cuando se encuentre perdido en alguna derivación poco pertinente. Los objetivos serán pautas a tomar para constituir el índice del futuro libro, ya que estructuran visceralmente a la investigación en tanto son los resultados esperados al momento del diseño y los temas tratados en la investigación. El marco teórico no se colocará así, con esa denominación en la investigación, pero se diluirá en la introducción, a fin de contar al lector las bases que tiene el tesista para investigar. El mismo sitio será ocupado también, al principio, por la metodología, para que el lector sea prevenido de los caminos y pasos que deberá tomar si quiere controlar las afirmaciones del tesista.

Por el lado de la acción de la investigación sobre el diseño, los productos científicos terminados ejercen una influencia a la hora de redactar los diseños: sea en la forma de los propios trabajos del tesista, de los cuales puede valerse para ayudarse a escribir la nueva investigación, tomando lo bueno y mejorando en lo deficiente, o sea en la forma de trabajos ajenos que lo ayudarán a imitar lo valioso y sobrepasar lo deficiente. Nótese cómo el caudal de investigaciones pertinentes al tema a tratar ayuda a completar el elemento antecedentes, cómo los manuales de metodología contribuyen a la redacción del elemento homónimo; cómo la enseñanza de la creatividad ayuda a sortear con éxito los obstáculos que el consciente pone para el surgimiento de nuestro deseo de la investigación.

\section{Contexto de aplicación}

Muchas licenciaturas plantean al finalizar la carrera, una especie de mea culpa, en donde llaman al alumno a la "integración curricular", y entonces el estudiante debe hacer el esfuerzo de articular, juntar, comunicar, cuando no fue entrenado en esas operaciones, y le resulta entonces sumamente complicado y difícil. Cuando podría haberse planteado la idea desde un principio y hacer ejercicios articulatorios o integradores en cada 
una de las asignaturas de la carrera de que se trate. Sin perjuicio de la sistematización de dichas relaciones en una Epistemología, sobre todo para aquellas carreras que no la tienen. Es necesaria “[(...) una reorganización en cadena de la estructura del saber" (Morin, 1993, p. 37). Es decir, la articulación debe ser transversal o, en otras palabras, verse y ponerse en práctica en cada materia, o dentro de la carrera, mediante ciclos articulatorios a lo largo de aquella. En el caso del Derecho, o no hay ideas articuladoras, que no se traducen en dicha asignatura, o hay atisbos de ello en materias tales como Teoría General del Derecho en donde se plantea la relación entre ramas, pero en el caso de la UNR es una materia marginal en tanto es optativa.

Otra aplicación concreta de la integración se da en el perfil del egresado de una carrera en particular, en donde se da una formación básica, que puedo llamar disciplinar, y luego, el estudiante se va especializando al finalizar la carrera con la elección de determinadas materias, que tomarán contacto con otras disciplinas, dándose la integración en el propio plan de estudios $\underline{53}$. La Universidad de Buenos Aires plantea esto aunque la especialización se da al interior del Derecho, afinando en el marco jurídico, con el CPO (Ciclo Profesional Orientado). También puede hablarse de la integración disciplinar, en donde distintas disciplinas toman contacto.

\section{Conclusión}

Se logra la idea de “metodologización”, que encierra la investigación en los métodos como recetas. Se exponen las ventajas y desventajas u obstáculos que debe sortear la interdisciplinariedad. Se ven las implicancias de la filosofía integradora, compleja y transdisciplinaria, en un diseño de investigación. Se aporta la categoría transdisciplinar de la propiedad, sumándola a la de producción.

En el contexto lógico se abordan las distintas maneras de fundamentar, describir y encuadrar la complejidad y la transdisciplinariedad en términos metodológicos: la triangulación, la combinación de herramientas, modelos (tradiciones) y tipos de investigación, y la complementación. Se alude a la articulación intrametodológica (repetición, variación), a la integración intermetodológica (creación), y la incertidumbre metodológica. El caso de la investigación-acción plantea el dilema/aporía de la investigación como conocimiento o transformación.

A partir de la estructura del diseño de investigación, se plantean estrategias metodológicas transdisciplinares asistemáticas, y sistemáticas, elemento por elemento del diseño metodológico. Como otro de los resultados se agrega la creación de la categoría Teoría General/Provisoria de la Ciencia, encarada desde la transdisciplinariedad.

El Pensamiento Complejo nos enfrenta a desafíos y uno de ellos es el metodológico, de manera de poder combinar sin mutilar ideas contradictorias al interior de la Metodología, y así valernos de ella pero sin metodologizar la aventura del conocimiento.

Notas

$\left.1{ }^{*}\right)$ Centro de Altos Estudios en Ciencias Sociales, Universidad Abierta Interamericana (UAI), Rosario, Argentina. www.elvioacademia.wordpress.com

“La transdisciplinarité, après la pluridisciplinarité et l'interdisciplinarité, y apparaît comme l'une des solutions possibles en réponse à l'explosion disciplinaire et à ses conséquences mais aussi comme une nouvelle approche riche de promesses liée aux nouveaux impératifs de la science” (Paul, 2005, p. 8). "La transdisciplinariedad, según la pluridisciplinariedad y la interdisciplinariedad, aparece como una de las soluciones posibles en respuesta a la explosión disciplinaria y a sus consecuencias pero también como una 
nueva aproximación rica en promesas ligadas a los nuevos imperativos de la ciencia” (trad. del autor).

$\underline{2}$ Sobre el tema véase Galati, E. (2016), Una perspectiva jurídica compleja de la medicalización de la vida y la juridización de la salud (inédito).

$\underline{3}$ Esto es lo que inspira la crítica a la Filosofía Analítica, que pretende reducir la Filosofía al análisis lógico del lenguaje.

4 Algo similar plantea Goldschmidt con lo que denomina la “complejidad impura”, que implica mezcla, confusión, frente a la “complejidad pura”, donde se mantiene la multiplicidad en armonía sistemática. Véase: V. Goldschmidt (1987); Galati, E. (2012); Galati, E. (2009).

$\underline{5}$ “Estamos en el registro de lo analítico, donde la descomposición es de rigor” (trad. del autor).

$\underline{6}$ “'...] las disciplinas no son solamente un medio cómodo de dividir los conocimientos en elementos, ellas son también la base sobre la cual la Universidad se organiza en feudos autónomos que definen las diferentes especialidades de la enseñanza y la investigación” (trad. del autor).

7 “La transdisciplinariedad aplicada deviene difícilmente concebible sin inversión personal (disciplina interna) y sin solidaridad (interacción)” (trad. del autor).

$\underline{8}$ Sobre el tema p. v. Galati, E. (2008). El mayo francés como r-evolución. Sus relaciones con el pensamiento complejo y el trialismo. Obtenida el 2 de marzo de 2012 de http://www.sasju.org.ar/encuentros/ix/sasju2008/comision 08/galati 08.pdf

$\underline{9}$ Sobre el tema p. v. Galati, E. 2015.

$\underline{10}$ “Una misma persona puede dedicarse con constancia a distintas ciencias” (trad. del autor).

11 "El especialista, en cuanto a él, se acomoda muy bien en un discurso que lo asegura, lo protege y detrás del cual se resguarda” (trad. del autor).

$\underline{12}$ “La agenda de esta discusión está fuertemente incidida por la controversia en torno a la caracterización de la crisis de la Modernidad”. Lanz, 2010: 12.

$\underline{13}$ V. tb. Foucault, M. (2008). La vie: l'expérience et la science. En J.-F. Braunstein (coord.), L’histoire des sciences. Méthodes, styles et controverses (pp. 345-362). Paris: Vrin.

14 V. en el Derecho lo que sugiere Guibourg, R. (1973). La justicia y la máquina. La Ley, t. 150, pp. 9941004. Lo que sería una suerte de mecanología jurídica.

15 Sobre el tema p. v. Galati, E. (2013).

16 Recuérdese que Platón también hablaba de un comunismo pero político, no económico.

17 Por el contrario, el adiestramiento, la domesticación en un área o tema, acostumbra al científico a ver lo que todos ven.

18 En otro momento inferiré más directamente pautas metodológicas de la complejidad y la transdisciplinariedad.

19 En un sentido similar p. v. Nieto Caraveo, 1991: 7 y Mourad, 1997: 15.

$\underline{20}$ “(...) auténtica integración, que se diferencia de las anteriores en que ambos métodos se orientan ahora al cumplimiento de un mismo propósito, al análisis de un mismo objeto de la realidad social”. Arroyo Menéndez (2008), pp. 205-206. 
21 "La interdisciplinariedad (...) no emerge espontáneamente por el hecho de que varios especialistas trabajen juntos”. (Cea D’Ancona, 1999, p. 93).

$\underline{22}$ Cuando se critica la instrumentación de lo cualitativo a lo cuantitativo, o que la integración debería ser más igualitaria, se vuelve a poner polémica en las distintas trayectorias de investigación. “(...) la dificultad de reducción del objeto de estudio a ítems o índices sin romper la estructura, articulación y sentido del mismo (...)”. (Arroyo Menéndez, 2008, p. 202).

$\underline{23}$ La combinación no tiene por qué ser necesariamente subsidiaria, en donde predomine en el diseño o la investigación una tradición metodológica. V. Arroyo Menéndez, 2008: 205.

$\underline{24}$ "La confrontación de este saber experiencial con los saberes teóricos de los universitarios permitió a los militantes ir todavía más lejos en la explicación” (trad. del autor).

$\underline{25}$ “Sesiones narrativas de prácticas y entrevistas de explicación (...) permitieron formalizar estos saberes específicos” (trad. del autor).

$\underline{26}$ Esto se parece a lo que en Gnoseología se llama la filosofía, la ciencia y la técnica, en tanto la primera desarrolla lo general en el conocimiento, la segunda se plantea problemas y trata de resolverlos a través de hipótesis que predicen, y la tercera refiere a la aplicación de procedimientos ya probados y que tienden a la obtención de un resultado concreto.

$\underline{27}$ Sobre el tema p. v. Galati, E. (2015). Filosofía y práctica de la investigación científica. Acerca de los objetivos de conocimiento y los objetivos de transformación. XI Jornadas de Sociología: Coordenadas contemporáneas de la Sociología: tiempos, cuerpos, saberes.

$\underline{28}$ Las anteriores serían integraciones "intermetodológicas”.

$\underline{29}$ “(...) el pasaje del conocimiento a la acción (...) exige una interdependencia de disciplinas y engendra incluso disciplinas nuevas” (trad. del autor).

$\underline{30}$ “( ...) correspondance entre les structures (...)". “(...) correspondencia entre las estructuras (...)” (trad. del autor).

$\underline{31}$ Aquí se plantea a la interdisciplina como algo que va contra la corriente de la ciencia, y entonces no es algo que surja espontánea ni naturalmente. Mientras que la investigación disciplinar no es algo infructuoso, al contrario. El artículo también pone en contexto a la interdisciplina, limitándola y no convirtiéndola en una simple receta mágica que resolverá los problemas (de la educación en ese caso).

$\underline{32}$ "El hecho de que el hombre sea capaz de acción significa que cabe esperar de él lo inesperado, que es capaz de realizar lo que es infinitamente improbable. Y una vez más esto es posible debido sólo a que cada hombre es único, de tal manera que con cada nacimiento algo singularmente nuevo entra en el mundo". Arendt, 2009, p. 202.

$\underline{33}$ Ya hablé sobre la historia y los lineamientos filosóficos de la transdisciplinariedad en Galati, 2015.

$\underline{34}$ “(...) le langage philosophique décloisonne les territoires réservés” (Resweber, 1981, p. 119). “(...) el lenguaje filosófico liberaliza los territorios reservados” (trad. del autor).

$\underline{35}$ Incluso el autor hace referencia a la complejidad, sin nombrar a Edgar Morin o sus autores afines. (Mittelstrass, 2011, p. 330).

$\underline{36}$ Sobre el Derecho y la Complejidad p. v. Galati, 2012 y Galati, 2009.

37 Klimovsky, G. y Schuster, F. (2000). Descubrimiento y creatividad en ciencia. Buenos Aires: Eudeba. 
$\underline{38}$ Paul Feyerabend se pronuncia en el mismo sentido. Feyerabend, P. (1990). Diálogo sobre el método. Madrid: Cátedra.

39 "La epistemología transdisciplinaria permite aquí aprender mejor las relaciones posibles entre aproximaciones contradictorias y poder articularlas en lugar de oponerlas” (trad. del autor).

$\underline{40}$ La ventaja de la UNR es que cuenta con el CIDOC (Centro de Documentación e Información Científica). P. v. http://bibliotecas.unr.edu.ar/biblioteca virtual/bibliotecas/cidoc/cidoc.php (29.3.2011).

$\underline{41}$ ¿Alguien dudaría del premio Nobel de Química que se le dio a Ilya Prigogine? Si viene la explicación de las ciencias duras, es incuestionable lo dicho.

42 Sobre el tema p. v. Galati, 2009 y 2012.

$4 \underline{3}$ V. Galati, 2009 y 2012.

44 V. Galati, 2016.

45 Galati, E. (2013). Estrategias para la construcción de Derecho. A propósito del matrimonio minoritario/igualitario en Argentina. II Jornadas Nacionales de Teoría General del Derecho. Buenos Aires: Universidad de Buenos Aires.

$\underline{46}$ “(...) no solo los objetos definen la disciplina, sino nuestra manera de tratar con ellos en la teoría” (trad. del autor).

$\underline{47}$ “(...) una abertura perforada en un muro forma un pasaje entre dos piezas; este vacío crea el lazo entre dos espacios); del mismo modo que la ruptura que es igualmente un lazo. Por su existencia, la ruptura construye un nuevo lazo. Como el marginal (...) su ruptura social es la expresión de lo que lo religa a la sociedad. La ausencia de lazo puede ligar; la ausencia implica la presencia; el no-lazo es un lazo” (trad. del autor).

$\underline{48}$ “(...) ella deshace las rigideces disciplinares siempre que ello obstruya la formación de problemas y sus correspondientes acciones de investigación (...)” (trad. del autor).

49 Sobre el tema p. v. Mardones, J. M. y Ursua, N. 1999: 73-114.

$\underline{50}$ De hecho una de las bases de este trabajo implica metodologizar la transdisciplinariedad.

$\underline{51}$ “Este orden de la ciencia se vuelve contraproducente” (trad. del autor).

$\underline{52}$ Sobre el tema p. v. Galati, E. (2016). Filosofía de la gestión de la ciencia en Argentina a partir de la historia del CONICET. Cinta de Moebio. Revista de Epistemología de Ciencias Sociales, 55, 80-95. Nótese también el engendro del "emprendedurismo”, producto de la dinámica de algunas universidades privadas que necesitan recursos para subsistir. “(...) una óptica transdisciplinaria tiene una repercusión inmediata en la gestión del conocimiento, en las políticas públicas de ciencia y tecnología. De nuevo aquí es preciso desmontar todo un sistema de prácticas, discursos y aparatos que están estructurados según el viejo paradigma de la 'ciencia normal' (...)”. Lanz, 2010, 18.

$\underline{53}$ Lo que se da en la Lic. en Antropología de la Univ. Nac. de la Plata. Sobre el tema p. v. Teves, 2009.

\section{Bibliografía}

Apostel, L. (1972). Les instruments conceptuels de l'interdisciplinarité: une démarche opérationnelle. En L. Apostel et al. (eds.), L'interdisciplinarité. Problèmes d'enseignement et de recherche dans les universités (pp. 77-82). Paris: Organisation de Coopération et de Développement Économiques. 
Arana, J. (2001). ¿Es posible la interdisciplinariedad?. Obtenida el 25 de agosto de 2011, de http://www.pensamientocomplejo.com.ar/docs/files/arana_es_posible_la_interdisciplinariedad.pdf

Arendt, H. (2009). La condición humana. Buenos Aires: Paidós.

Arroyo Menéndez, M. (2008). Cualitativo-cuantitativo: la integración de dos perspectivas. En A. Merlino (coord.), Investigación cualitativa en Ciencias Sociales. Temas, problemas y aplicaciones (pp. 195-208). Buenos Aires: Cengage Learning Argentina.

Barbier, R. (2003). L'éducateur et le sacré aujourd'hui. En B. Nicolescu (dir.), Le Sacré aujourd'hui, précédé d'Hommage à Michel Camus (pp. 176-184). Monaco: du Rocher.

Berger, G. (1972). Opinions et réalités. En L. Apostel et al. (ed.), L'interdisciplinarité. Problèmes d'enseignement et de recherche dans les universités (pp. 19-74). Paris: Organisation de Coopération et de Développement Économiques.

Buguet, J. (2003). Pour une pédagogie du lien: pluri, inter et transdisciplinarité en formation BTS (Brevet de Technicien Supérieur). En JN. Demol (coord), Didactique et transdisciplinarité (pp. 129-154). Paris: L'Harmattan.

Cea D’ancona. M. A. (1999). Metodología cuantitativa: estrategias y técnicas de investigación social. Madrid: Síntesis.

Comesaña, J. M. (2001). Lógica informal, falacias y argumentos filosóficos. Buenos Aires: Eudeba.

Demol, JN. (Coord.). (2003). Introduction Générale Problématisant. Didactique et transdisciplinarité (pp. 744). Paris: L'Harmattan.

Descartes, R. (1993). Discurso del método. Barcelona: Altaya.

Follari, R. (2001). Estudios culturales, transdisciplinariedad e interdisciplinariedad (¿hegemonismo en las ciencias sociales latinoamericanas?). Utopía y Praxis Latinoamericana, 14, 40-47.

Follari, R. (2007). La interdisciplina en la docencia. Polis. Revista Latinoamericana, 16, 1-12.

Galati, E. (2013). El pensamiento complejo y transdisciplinario en la enseñanza de "la internacionalidad". Anuario Argentino de Derecho Internacional, t. XXII, 279-341.

Galati, E. (2015). Los comités hospitalarios de bioética. Una comprensión trialista y transdisciplinaria desde el Derecho de la Salud. Buenos Aires: Teseo-UAI.

Galvani, P. (2005). Fertilisation croisée des savoirs et ingénierie d’alternance socio-formative. Le programme de recherche-formation-action Quart Monde-Université. En P Paul y G. Pineau (coords.), Transdisciplinarité et formation (pp. 31-46). Paris: Harmattan.

Galvani, P. (2008). Quelle formation pour les formateurs transdisciplinaires? Obtenida el 30 de junio de 2010, de http://basarab.nicolescu.perso.sfr.fr/ciret/ARTICLES/Galvani fichiers/Galvani.pdf

García, R. (2006). Sistemas complejos. Conceptos, método y fundamentación epistemológica de la investigación interdisciplinaria. Barcelona: Gedisa.

Gass, JR. (1972). Préface. En L. Apostel et al. (eds.), L'interdisciplinarité. Problèmes d'enseignement et de recherche dans les universités (pp. 7-8). Paris: Organisation de Coopération et de Développement Économiques.

Goldschmidt, W. (1987). Introducción filosófica al Derecho. Buenos Aires: Depalma. 
Hogarth, R. (2002). Educar la intuición. El desarrollo del sexo sentido. Buenos Aires: Paidós.

Kant, I. (2006). Crítica de la razón pura. Buenos Aires: Losada.

Kelsen, H. (1992). Teoría pura del Derecho. Buenos Aires: Eudeba.

Kuhn, T. (1996). La estructura de las revoluciones científicas. México: Fondo de Cultura Económica.

Lanz, R. (2010). Diez preguntas sobre transdisciplina. Revista de Estudios Transdisciplinarios, 2(1), 11-21.

Maclure, S. (1991). Introducción: panorama general. En S. Maclure y P. Davies (Comps.), Aprender a pensar, pensar en aprender, trad. de Daniel Zadunaisky (pp. 11-32). Barcelona: Gedisa.

Mardones, J. M., y Ursua, N. (1999). Filosofía de las ciencias humanas y sociales. Materiales para una fundamentación científica. México D. F.: Coyoacán.

Ministerio de Educación de la Nación (2008). Documento metodológico orientador para la investigación educativa. Buenos Aires: Organización de los Estados Iberoamericanos para la Educación, la Ciencia y la Cultura.

Mittelstrass, J. (2011). On transdisciplinarity. Trames: A Journal of the Humanities \& Social Sciences, 15(4), 329-338.

Morin, E. (1993). El Método 1. La naturaleza de la naturaleza. Madrid: Cátedra.

Morin, E. (2011). La vía. Para el futuro de la humanidad. Barcelona: Paidós.

Morin, E. (1999). Los siete saberes necesarios para la educación del futuro. París: UNESCO.

Morin, E. (2003). Pensar Europa. Barcelona: Gedisa.

Mourad, R. (1997). Interdisciplinariedad post moderna. The Review of Higher Education, 20, 113-140.

Nicolescu, B. (2006). Transdisciplinarity - Past, present and future. Obtenida el 7 de setiembre de 2010, de http://basarab.nicolescu.perso.sfr.fr/Basarab/Docs_articles/Worldviews2006.htm

Nieto Caraveo, L. (1991). Una visión sobre la interdisciplinariedad y su construcción en los currículos profesionales. Revista de Ciencias Sociales y Humanidades, 5-6, 1-10.

Paul, P. (2005). Introduction. En P. Paul y G. Pineau (coords.), Transdisciplinarité et formation (pp. 5-10). Paris: L’Harmattan.

Piaget, J. (1972). L’épistémologie des relations interdisciplinaires. En L. Apostel et al. (ed.), L'interdisciplinarité. Problèmes d'enseignement et de recherche dans les universités (pp. 131-144). Paris: Organisation de Coopération et de Développement Économiques.

Pichon-Rivière, E. (2005). El proceso creador. Del psicoanálisis a la psicología social (III). Buenos Aires: Nueva Visión.

Pozzoli, MT. (2011). Modelo Teórico-Metodológico Transdisciplinario para Sujetos Complejos en Tiempos de Crisis. Complejidad, 12, 27-35.

Resweber, JP. (1981). La méthode interdisciplinaire. Paris: Presses Universitaires de France.

Salas, Á. (2004). La labor del filósofo. Dikaiosyne. Revista de Filosofía Práctica, 13, 11-36.

Saltalamacchia, H. (2005). Del proyecto al análisis: aportes para una investigación cualitativa (3 t.). Buenos Aires: el autor. 
Samaja, J. (1999). Epistemología y metodología: elementos para una teoría de la investigación científica. Buenos Aires: Eudeba.

Samaja, J. (2004). Proceso, diseño y proyecto en investigación científica. Buenos Aires: JVE.

Sautu, R. (2005). Todo es teoría. Objetivos y métodos de investigación. Buenos Aires: Lumiere.

Stolkiner, A. (1999). La interdisciplina: entre la epistemología y las prácticas. Obtenida el 7 de setiembre de 2003, de www.campopsi.com.ar/interdisciplina.htm

Teves, L. et al. (2009). 50 años de Antropología en el Museo de Ciencias Naturales de La Plata: historia, desafíos y perspectivas. Avá, 14. Obtenida el 20 de noviembre de 2010, de http://www.scielo.org.ar/scielo.php?script=sci arttext\&pid=S1851-16942009000100014\&lng=es\&nrm=iso

Zicavo, E. (9 de marzo de 2013). Desde la trinchera. Página 12. 